\title{
III.-ON THE INTERPRETATION OF PLATO'S PARMENIDES. (II.)
}

\section{By A. E. Taylor.}

A GOOD deal of discussion has been bestowed, as I think without need, on the question, What are the "One" and "Many" of the Parmenidean hypotheses? Is the "One" the supreme Idea which is elsewhere known as the "Idea of Good," and the "Many" consequently the rest of the contents of the Ideal world, or does the "One" represent any Idea and the "Many" the sensible particulars corresponding to it? As to this point, while we may notice that Parmenides expressly says $(136 \mathrm{~A})$ that the method is applicable to any Idea, his further specification (137 B) of the subject to be discussed as "his own" hypothesis of the One seems to decide for the first alternative and against the second. If what we are to examine is to bear any likeness to the Eleatic One, even as read by the light of a more developed metaphysic, then it must be no lower and partial kind of unity, but the ultimate unity of absolute reality, which we are invited to discuss. In more modern language, it is not simply the conception of system in general, but the conception of the world as an all-inclusive system, which Plato intends to unfold. This view is indeed so natural that its correctness would probably never have been questioned but for the following reflection. If $\tau \dot{o}$ êv be the absolute One it would seem that $\tau \grave{a} \ddot{a} \lambda \lambda a$ must be the world of subordinate Ideas. In that case however we shall be discussing not the old problem with which the first half of the dialogue was concerned, How is the Idea related to the particular thing? but a new and independent question of the relations of Ideas among themselves; and must therefore confess that we, like others, have failed to find a connection between the preceding pages and what follows. It seems therefore that, in spite of Parmenides' description of the subject under discussion, we ought to decide for the second of our two alternatives. Plausible 
as this argument is, it rests to my mind on a fallacy, and a fallacy of which the previous reasonings of Parmenides should have disabused us. It assumes that very distinction of two "worlds"-a sensible and an ideal-which we have felt ourselves constrained to abandon. While we still allowed that unhappy superstition to infect ou: understanding it was of course natural enough to argue that a discussion about relations in the ideal world could not at the same time be a discussion of the relation of the ideal to the sensible world. Now, however, that we have abandoned our earlier dualism, we should be able to see that, as the supposed "two" worlds are one world, so the "two" questions are only two ways of putting the same question. As soon as we realise what Plato is constantly trying to make us understand, that the "ideal" world simply means the real world in so far as it becomes an object for knowledge, we should have no difficulty in seeing that the problem how one "Idea" can be present to many "things" and the problem how one "Idea" can while preserving its unity enter into relations with many other "Ideas," are only two ways of raising the same question. For a thing, in the only sense in which a thing is knowable, is nothing more or less than a certain system of Universals, or, in Platonic phraseology, Ideas. There is, of course, about a thing as sensible a something more or less which makes all the difference between the thing as merely thought of and the thing as actually present to sense. From the nature of the case, however, no one can give any intelligible account of what that "something" is, ( $c f$. Plato's own language on a similar question, Tim. 51 B) and it has no bearing whatever on the difficulty with which we are concerned. The feat which we decided had to be accomplished if philosophy was to exist-the reconciliation of unity with diversity-confronts us just as much when we make any judgment about a thing which we merely think of as when we judge about a thing actually present to sense-perception. The conception of the world as a unity which can only exist so far as it is also a diversity is the answer, or part of the answer, to both problems. The proof that unity, so far from being incompatible with diversity, cannot exist without it, while dealing throughout with relations between Ideas, is the required solution of our difficulty about the connection of Idea and thing ${ }^{1}$.

I do not propose to present any scheme or abstract of the connection between the various hypotheses at the present stage of our discussion. Convenient as such a scheme would be, its accuracy could only be tested after a laborious comparison of

1 Cf. on this question Zeller, Platonicche Studien, p. 167, 168. 
its statements with the details afterwards to be given, and its proper place is where I have put it, at the end and not at the beginning of the enquiry. I will merely protest in passing against the misrepresentations which the desire for symmetry at any cost has introduced into some accounts of the hypotheses, notably Zeller's in Platonische Studien and Apelt's in Beiträge zur. Geschichte der Griechischen Philosophie. Neither of these writers has been able to resist the temptation to arrange the hypotheses in four sets of antinomies, each antinomy starting from a common presupposition. Such an arrangement however only succeeds in obtaining an external symmetry by disregarding Plato's own clearly marked divisions between the various arguments. If we attend carefully to the breaks in the text we shall in fact see that the real number of separate arguments is not eight but nine, though it is true that two (the second and third,) are so closely connected that they may without any serious inaccuracy be treated, as Zeller has treated them, as one continuous argument. The case is different with hypotheses 8 and 9, which Apelt throws into one in order to get his symmetrical arrangement of theses and antitheses. These two arguments are, as we.shall presently see, so far from being complementary that they actually exclude each other. To pass now to the consideration of the separate hypotheses in detail.

We may divide the hypotheses generally into two classes, (a) those which start from the affirmation of the world's unity;

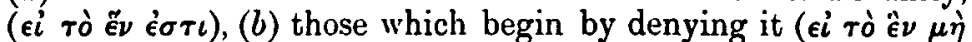
є $\sigma \tau \iota)$. Of the former class are hypotheses $1-5$ (137 c-160 B), of the latter numbers $6-9(160 \mathrm{~B}-166 \mathrm{c})$. In each of these two divisions we have a further sub-division; we trace first the consequences with respect to tò êv itself which follow from our original assumption $(1,2,3,6,7)$, next those which relate to $\tau \dot{\lambda}$ ă $\lambda \lambda a(4,5,8,9)$. We have thus four questions before us which may be tabulated thus:-

(1) If the unity of the world be affirmed, what judgments can we make about that unity? $(1,2,3$.)

(2) If the unity of the world be affirmed, wbat judgments can we make about its multiplicity? $(4,5$.)

(3) If the unity of the world be denied, what judgments can we make about that unity? $(6,7$.

(4) If the unity of the world be denied, what judgments can we make about its multiplicity? $(8,9$.

We shall however see directly that this arrangement of the hypotheses is based on the merely superficial characteristics of external form : their real relations of agreement and opposition we shall only be able to formulate at a later stage of our inquiry, after detailed examination of their contents. 
Hypothesis 1 (137 C-142 B), which we will now proceed to examine, introduces us to one way of answering our first question. We must notice first the exact character of the assumption with which we start. That assumption, as stated in the words $\epsilon i \ddot{E} \nu \dot{\epsilon} \sigma \tau \iota$, is a judgment of which only the predicate is enunciated, while the subject is left to thought to supply. This unexpressed subject is, as the course of the reasoning, as well as the linguistic usage, shows, $\tau \dot{o}$ ö $\nu$ or $\tau \dot{a}$ ö $\nu \tau a$, and the logical form of the hypothesis is therefore that of a judgment in which "unity" appears as the predicate which is affirmed of complete or absolute reality. We begin,-and this glaringly rash beginning will be the sole source of the perplexity in which we shall directly find ourselves, - by laying it down that a certain predicate is true of ultimate reality, and we then go on to exclude from that reality all other predicates which conflict with the one we have ascribed to it. This is done in detail as follows:Reality is one: therefore it is not many. Therefore it has no distinction of parts, and having no parts is not a whole. Similarly it has no definite limits or bounds, and no figure or shape: both would imply that distinction of parts which is by our hypothesis impossible. For the same reason it has no spatial position or extension: $(138 \mathrm{~A})$ it can neither be contained in anything else nor in itself. For if contained in anything else, it must touch that which contains it at various points, which is inconsistent with its perfect unity, and if self-contained, it will be different quà containing envelope from itself $q u \dot{a}$ contained, and this also is equally fatal to its unity. This argument may, I suppose, be paraphrased in more modern language thus. A world which is mere unity cannot have spatial determinations. For if, when we speak of the world as "being in" space, we think of space as in some way real independently of the world and enveloping it all round, we shall have to admit a multiplicity of relations between the world and the various points of space itself ${ }^{1}$; and if we treat space on the other hand as "being in" the world, it becomes a set of relations between one part of the world and the world as a whole, and thus in either case we introduce diversity and multiplicity into the original unity.

Once more, motion and rest are alike inconceivable in a world which is such a unity. For we may conceive of motion in the widest sense as either $(a)$ qualitative change or $(b)$ change of position. As for the first, its irreconcileability with bare self-identity is at once apparent. And the second is no less out of the question. For the change of position may be either relative or absolute. If relative-as in the case of rotation round

1 For otherwise we should have an extended world withont extension. 
an axis ${ }^{1}$-it implies just that distinction of parts in the world's unity which we refuse to recognise. And if absolute-i.e. if the whole world be conceived of as changing its place, we come to a double contradiction. For (1) we have already seen that the world as a whole cannot be in place at all, and (2) still less can it "come into" place: for it could only do so by the gradual entrance of first one part of itself and then another into the given space. But it has by hypothesis no distinction of parts. Every form of change and motion must therefore be excluded from the real world, if reality be a mere self-identical unit.

Neither can reality be "at rest" or "unchanging." For to be "at rest" or "changeless" means to remain " in the same state" in which you already are. And we have already seen that reality never is "in" any "state" or "position"." Thus "rest," "self-maintenance," or any other form in which we seek to express the permanent self-sameness of the intelligible world, proves in the end as unthinkable as its opposite.

But we may go much further than this $(139 \mathrm{~B})$. Dropping any spatial scheme or metaphor by which we have hitherto sought to understand what self-sameness is, we must raise the question whether any sameness with itself or any diversity from what falls outside it can be asserted of such an inteliigible world as we are trying to maintain. And we are driven to admit that these predicates can in no way attach to bare unity. The real is neither identical with nor different from itself or anything else. Two of these conclusions lie at once ready to hand, and would probably be endorsed by "common-sense" philosophy. The real cannot be different from itself nor identical with anything else: were it different from itself it would no longer be unbroken unity; and were it identical with something else it would be identical with what is other than unity, and therefore itself no longer unity. We can also see that it cannot be different from anything else $(139 \mathrm{c})$. For it is no part of the essence or nature of

1 This is the only form of relative change of place Plato mentions, but the argument is of universal application.

2 The vague nature of such expressions as iv rī avirü cival makes it peculiarly difficult to set out Plato's argument in another language in its full force. The reference here is of course to the previous proof that the unitary real is not "anywhere" (see abore). In translating into English it was unavoidable to make the spatial reference more exclusively prominent than it is in the Greek. But the reader will ensily see that the same considerations which disposed of space may be urged against any systematic relations, whether of the real world to anything outside itself or of elements in the real world to one another. We may then proceed to develop Plato's argument thus. To remain unchanged means to remain "in the same relations." But we have already seen that the real cannot be in any relations. Ergo, etc. 
unity to be relative to some other term and different from it. Hence if the supreme unity be different from anything else, it is not in its own right and of its own inmost nature that it has this quality of difference ( $\tau \hat{\omega} \mu \dot{e}^{\prime} \nu$ ăpa $\hat{\epsilon} \nu$ eival oủk

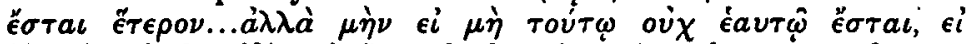

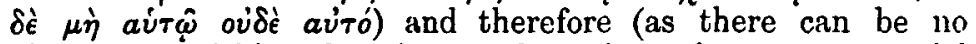
distinction within what is merely unitary between essential and unessential elements), the One is not in any way different from anything else. Neither is it really self-identical. For unity and identity are not the same thing: if both are predicable of reality they must be recognised as different aspect. of it; its unity will be one thing and its identity another, and consequently the self-identical One will contain an element of diversity. But this is just what our hypothesis forbids us to admit. Identity and difference must therefore both be surrendered. Likeness and unlikeness must now of course share the same fate. For likeness is partial identity (rò raùrò

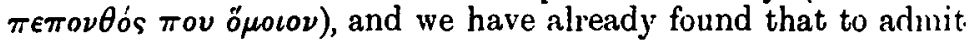
identity into the intelligible world is to adnit diversity along with it. Similarly the argument which proved fatal to difference forces us to exclude unlikeness. The same reasoning may be extended to any attempt to determine reality by quantitative predicates. It can neither be equal to, greatar, nor less than itself or anything else. For equality is a special form of identity, viz., identity in respect of quantity, and must therefore share the fate of identity in general. And any "more" or "less" when thought out implies parts. That is greater than something else which contains a greater number of equal parts; that smaller which contains fewer. Hence neither predicate can be applied to that which is ex hypothesi perfectly simple and indivisible. And thus quantitative distinctions have followed qualitative.

Lastly, can our One stand in any temporal relation whether of succession or of simultaneity? In principle these relations have been condemned already. For simultaneity is a new form of identity and, like all identity, cannot exist apart from diversity, while priority or posteriority is, in the same way, only another kind of difference or unlikeness. The one real is thereforc neither before, nor after, nor together with itself or anything else. It follows that it has no existence in time at all. For whatever has duration in time may be said at any moment to involve three different relations. At each successive in mment it is becoming posterior and therefore, by the same process, prior to itsclf, while it is of course throughout the whole time simultinerous with itself. And all these three relations have just bcen denied of the real. The real 
is in consequence absolutely apart from time. Thereforeand this leads us at once to the paradoxical result of our hypothesis-it neither has been, is, nor will be, has become, is becoming nor will become. But what never has been and never will be is obviously destitute of all reality. The One therefore is absolutely unreal, and consequently is not even one: if it were, it would thus have some degree of reality. And finally, as there can be no possible points of contact between the real, and the utterly unreal, the One cannot be made the subject of speech, perception, belief or knowledge. It is unknowable, for the very best of reasons, - that it is only another name for nothing. Such is the necessary but altogether unbelievable consequence of our original supposition.

Thus the first of the Parmenidean hypotheses ends with the disproof of the very assumption with which it had set out. And the disproof has been perfectly serious and perfectly valid. Our impossible result has been due not to any skilful sophistry or ingenious quibbling in the argument, but to the secret error involved in the premiss from which we started. That premiss was that the intelligible or real world was a unity, and - as we tacitly added - a unity from which diversity is altogether excluded. And the irony of the Platonic method has consisted in turning this false assumption against itself. At each step of the argument the assumed incompatibility of unity with diversity has been recurred to to establish two opposite sets of conclusions. It has first been applied in principle much as the historical Eleatics or Megarians might have applied it, to show the absurdity of all predicates which openly ascribe multiplicity to the real world, and then in immediate succession to prove the equal inconceivability of those opposite determinations by which the Eleatics and their successors have sought to express their conviction of the world's unchanging self-sameness. Eleatic and Atomist, Megarian and Sensationalist are thus concluded in one common unbelief. The determination to take unity by itself as the absolutely real, and whatever is other than unity as simply unreal, has been found to lead to the complete severance of the world of appearance from the world of reality, and next and through this severance to the abolition of the latter world itself. Step by step, every predicate with which the Eleatic and the Megarian have invested the world of reality has been handed over to the world of mere appearance, till finally, on the unimpeachable principle that what has no qualities and produces no effects is nothing, its very existence has been pronounced to be illusion and mistake. There is nothing to know-such is the result to which we have been forced-and 
you can know nothing about it. Such a result, I need not say, would be the death-warrant of all science, and it is not surprising that both Parmenides and his respondent refuse

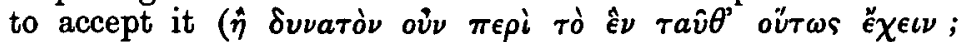

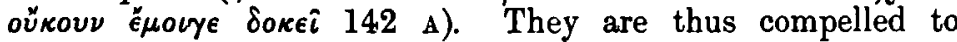
retrace their steps and once more to investigate the consequences which flow from. the admission that the world is a unity, and this bring us to the second of the nine hypotheses.

The second hypothesis $(142 \mathrm{~B}-15 \mathrm{~J} \mathrm{E})$ is the longest and by far the most intricate and difficult piece of argumentation in the dialogue, and will necessarily give us some trouble before we have done with it. Fortunately however, whatever may be its difficulties in detail, there can be no doubt about the general point of view by which it is distinguished from the preceding hypothesis. Plato does not, like the writer of a set Handbook to Metaphysics, stop to point out in so many words what was the flaw in our first crude conception of the world's unity, and in what way that conception is to be emended, but the first steps of the renewed discussion of themselves indicate the change in standpoint with perfect clearness. We started before with the hypothesis "Reality is unity"; we are now to start from "Unity is real." In the first case unity was taken as the sole predicate of a reality not otherwise definable; it is now to be taken, grammatically as the subject of an existential judgment, logically as one predicate among others of a reality which is not identical with itself. And this difference of starting-point leads to a similar difference in procedure. We began before by assuming that we knew already exactly what kind of unity the world possesses, and we then went on to rule out of the real world whatever predicates refused to combine with it: we shall now more modestly and philosophically begin by reminding ourselves that the unity of which we are in search must before all things be compatible with the general nature and universal conditions of real existence, and we shall go on to see what qualifications and restrictions this general nature of reality imposes upon it. What is one cannot be anything else but one was the axiom of our first hypothesis; what is one must nevertheless be real will be the axiom of the second. The consequence of this change of attitude, as we are now to see at large, will be that, whereas previously all predicates were excluded from reality, all will now be; in various senses and different relations, attached to it. In proceeding to paraphrase the reasoning by which Plato seeks to establish this important result, I am bound to warn the reader that while the general drift of the lengthy argument is to my mind unmistakeable, 
I do not by any means feel the same confidence in my own interpretation of all the details: in particular, in several places, to which I shall call atiention in the course of my exposition, I can hardly profess to have done more than hazard a tolerable guess at Plato's meaning.

We start then from the assumption "unity is real." This judgment, like all other judgments, is more than a mere identity. "Unity is real" is not simply another way of saying "unity is unity." Unity and reality then are not merely identical; they are complementary aspects of the full reality. And if " unity" and "reality" are distinguishable aspects within a whole, then the whole will be that "real unity" of which both are predicable, and either aspect may be called a "part" of the whole. Thus if the ultimate unity be also real it can only be in the form of a whole within which aspects which are distinct nevertheless come together. These aspects or "parts," as Plato calls them, are in the widest sense two,the ideal unity, or as we may say, if we will carefully keep the notion of conscious teleology out of our heads, the plan of the world, and the reality in which that plan is carried out. And within each of these aspects of the single reality when examined in abstraction from the other the same division repeats itself (142E). The "unity" and the "reality" alike contain both of the same twin aspects which constitute the whole. That is, I suppose, the "system" or "plan" which we set on one side as one of the two interacting factors turns out to be a "system of systems," while the "material" in which it is realised has to be thought of as already organised into a variety of subordinate systems. And this process of subdivision has no perceptible limits. However far you carry the distinction of "form" and "matter," or "reality" and "ideality," you never come across any element of reality which does not involve both. Thus, as Plato says, whatever "part" you take of reality you always find these same two "parts" within it, and the original unity, just because it must be real, must also exist in the form of an indefinite plurality or multiplicity of "parts" (143 A). Again, just as we have shewn that a real unity presupposes parts, we may by the same methods of reasoning show that the "unity" even taken in abstraction from the reality presupposes a plurality of numbers. For, taking them merely as abstract determinations of thought without any reference to the concrete character of the whole which they constitute, unity is other than reality and reality than unity. Hence arises a third abstract thought-determination, "difference," which is not identical with either of the two former (143B). These abstract forms of thought, like 
everything else which is capable of distinction, leud themselves to the process of counting: we get "unity," one, "reality," two, "diversity," three: or "diversity," one, "unity," two, "reality," three, and so on. Thus a mind-it is in this way I understand Plato's rather minute argumentation-which can form the thought of "one" and distinguish it from other thoughts is at once driven forward, even if it has nothing but its own abstractions to count, to form the ideas "two" and "three." And from two and three, the first even and the first odd number, can be derived by successive multiplication the whole numerical series (144 A) which is, of course, unlimited ${ }^{2}$.

Thus the admission of unity as a determination of the real brings with it the equal admission of the whole numerical series which arises logically from it. Reality is thus so far from being a mere self-identical unit that it is shared among an indefinite number of subjects, and is present in everything that has any kind of existence, be it great or small (144 B). We might indeed have reached this conclusion more directly, for there is a patent absurdity in the notion that anything that has existence should be completely devoid of reality. Reality is thus manifestly cut up and sundered into a perfectly unlimited number of different "parts" or "aspects," and is so far from being merely a unit that we may say there is nothing else so hopelessly torn by internal divisions ( $\pi \lambda$ ei $\sigma \tau a$

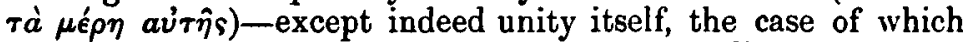
is equally desperate. For each "part" of reality so long as it exists is one definite part ; otherwise we should have parts which were yet no parts and things which were nothing. Thus for every division in the internal constitution of reality there is a corresponding rent in its unity. Each and every part is a unit and yet the whole so constituted is a unit also. We have seen $\tau \dot{o} \stackrel{e}{e} \nu$-if I may indulge in a slightly fantastic metaphor-already producing the whole infinite numerical series out of its own bowels; we now find it begetting by fission an innumerable multitude of lesser ones, each of which seems as much a unit as itself. So $(144 \mathrm{E})$ unity is compelled by its conjunction with reality to disappear in an infinity of 'fractions. This brings us to the first of the conclusions which we are entitled to draw from the conception of the world as a unity. "Not only is reality many, but unity itself from its connection. with reality necessarily divides up and becomes a plurclity."

1 Plato has overlooked or omitted the case of "prime" numbers, which

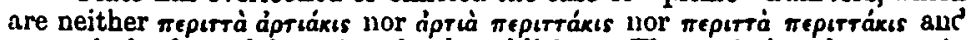
ciul only be formed from 2 and 3 by additiou. The omission does not in ang way affect the principle of the argument. 
Being now perfectly clear on this fundamental point, we may make the attempt once more to vindicate for reality the various classes of predicates which the repeated application of the principle that unity is incompatible with diversity compelled us successively to surrender. We begin as before with relations of a spatial character. The world of reality, being, as we have seen, a system of parts forming a single whole, must be "limited" or "finite," in the sense that the parts are contained within, and completely determined in every way by, the general character of the whole. We may speak therefore of the whole as "limiting," or quite literally "determining," its subordinate parts, and we have to add to the statement that reality is numerically infinite the correction that it is also finite. But, proceeds Plato, if finite it has boundaries, and, as a whole, it has beginning, middle, and end, of which the second is equidistant from the first and third. It can therefore have the spatial qualifications of extension and figure. In judging of the value of this argument we must take care to keep in mind the peculiar nature of metaphysical proof. There can of course be no such thing as an a priori demonstration that reality must appear in a spatial form and in no other, If our ordinary experience did not make us acquainted with the fact that reality does appear in such a form, we certainly could not have made the discovery for ourselves. All we can do is, now that we have learned from experience that things do appear as in space, to ascertain what are the leading characteristics of spatial existence, and convince ourselves that they are not inconsistent with the general nature of the reality which we suppose to underlie all appearances. And this is the character of the reasoning in the present passage.

It is shown that the unity of the world is not merely consistent with diversity, but actually demands for the manifestation of itself a concurrent diversity which is combined into a definitely ordered system; and such systematic relations are familiar to us, among other forms, in the shape of figure and extension in space. There is therefore nothing in the character of spatial relations incompatible with their being a mode of the appearance of what is ultimately the single reality. We are not bound in the interests of our belief in the fundamental unity of the real to treat the spatially extended as simply unreal, and we may therefore accept it on the authority of experience as one aspect among others of reality. Thus understood, as a defence of the partial reality of the spatial world against the objections of the first hypothesis, the argument will, I think, be found to be sound. It is of course possible that Plato looked upon it as being more than 
this: the very vagueness and allusiveness of the terms em-

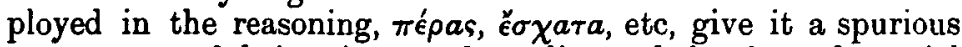
appearance of being just such a direct deduction of spatial relations from the general nature of the Absolute as we have called impossible.

From spatial relations we proceed to all those other leading characteristics of the world of actual experience which our first hypothesis banished one by one from the world of reality. (1) The one reality is self-contained. For each and all of the parts or aspects of the whole are contained by the whole without exception. And the whole which contains them all contains them without excess as without defect: for there is nothing in the world but what is in the parts. Thus when we say that the whole contains the parts we are saying that one and the same reality appears both as what contains and as what is contained: we are ascribing to it a permanent selfcontainedness. (2) And yet the one reality is outside itself. For though the parts are contained in the whole we must not say that the whole is contained in the parts. For if it is in all together it must be in each separately ; while just because it is the whole it cannot be in each single part nor in any number short of the total. It is therefore, from this point of view, not self-contained, and as that which is nowhere is nothing, must be permanently outside itself and appear in a foreign medium ( $\dot{\epsilon} \nu$ $\tilde{a} \lambda \lambda \omega)^{3}$. We may therefore restore to the list. of predicates which are true of the real both (3) permanent rest or changelessness and (4) perpetual change or motion. For in so far as the one reality remains always self-contained and self-identical it is for ever free from every form of change and disturbance, and is thus always at rest; while in so far as it is never self-contained but always manifests itself in a foreign medium it is always undergoing change. Thus the second point which we have reached is the affirmation about reality in one sense and the denial in another of the most prominent characteristics of the perceived worid : reality both is and is not self-contained, is always and is never at rest or in motion. (146 A.)

Of all the reasonings of Parmenides in this hypothesis the latter part of the present argument is perhaps that of which it is the most difficult to perceive the exact meaning and force. T'wo points call for special remark.

(1) With what warrant is it assumed that the whole cannot be contained in all its parts taken collectively unless it is also

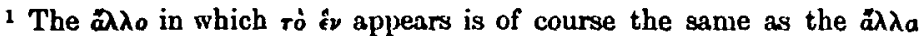
which are called its "parts." This is made certain by comparison of $140 \mathrm{E}$

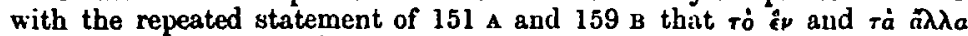
between them exhaust the content of existence. 
contained in each severally? Not merely is no proof offered of this assertion, but it seems on reflection of very doubtful truth. No conception is more familiar to us than that of a whole which is the sum of its parts: in geometry and still more in arithmetic the wholes with which we deal are entirely of this kind, and it certainly seems as if the principle which Plato here assumes as self-evident would, if accepted, make the latter science impossible. For it would at once dispose of all equations in which a total obtained by addition or multiplication is substituted for the sum or product of its factors. $12=7+5$ we believe to be true, and yet it is certain that $12=5$ or $12=7$ is false, though on Plato's principle either all three judgments should be true or all three false. (2) And further in the argument from the externality to self of reality to its perpetual motion is there not a subtle subreption? All that the foregoing proof, even if we overlook our misgivings about its premisses, establishes, is that the one reality somehow exists " Plato undertakes to deduce from this the perpetual motion of the real he substitutes for the words $\dot{\epsilon} \nu$ a $\lambda \lambda \lambda \omega$ eiva

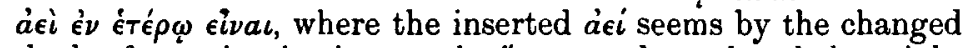

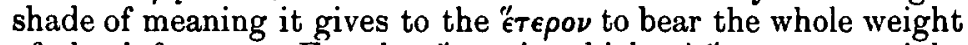
of the inference. For the a $\lambda \lambda \lambda_{0}$ in which $\tau \dot{0} " z \nu$ appears might for all that we know to the contrary itself be something fixed and unchanging: the addition of the a $i$ creates a grammatical ambiguity which secretly introduces into the premisses the very notion which we are seeking to infer from them. To these serious objections I can only offer the following rejoinder for what it is worth.

(1) The principle that if a whole be contained in its parts taken all together it must be in each severally is certainly not universally true. In the case of numerical, and to a less degree of geometrical, wholes it is distinntly false. For the special character of a numerical, as distinguished from any other kind of whole, is that it is simply the sum of its component parts taken in any order you please, and nothing more. The relation by which the parts are formed into the whole is simply one of juxtaposition. And-with the added restriction that in this case the parts must be combined in a particular order-the same is true of geometrical wholes. The principle becomes valid however if we make, as I suppose Plato must be making, the tacit assumption that the unity that reality possesses is not that of mere juxtaposition in space, but is rather analogous to an all-pervading plan or system in accordance with which the behaviour of any subordinate part of the whole is determined. If this be the case it is clear that though the single plan of the whole contains no element which is not supplied by its parts, 
yet the whole itself is something more than the sum of the parts. We may illustrate this by reference to any elaborate mechanical system, as e.g. the works of a watch. The unity which in this instance pervades the whole is that of a definite plan to the realisation of which each part of the whole has to contribute its share. And it is manifest that while there is no single part of the work to be done which is not performed by some one particular cog or wheel, no mere summation of the separate wheels will give you the whole. For even if by some lucky chance you arrange the separate parts in their proper order, you have still not got the whole: you do not arrive at that until you have set the machinery to work so as to produce the realisation of a plan or idea which is not contained in its fulness in any of the parts nor in any stationary arrangement of them all. Thus of all such wholes as consist in the realisation, by means of the working of subordinate parts, of a general plan or idea it is true to say that, while the whole contains the parts, the parts as such do not contain the whole. It "transcends" them as well as "inheres in" them.

(2) With regard to the second difficulty, I would recall what I have already said about the peculiar character of metaphysical proof. The existence of motion can no more be demonstrated from general principles than that of space. All we can do is to show, against negative criticisms, that the prominent peculiarities of motion are not such as to conflict absolutely with the kind of unity which it is reasonable to ascribe to reality. If we can do this we are entitled to conclude that there is no reason why motion should not attach in some way, as a partial appearance, to a reality which is at the same time one and self-identical. And so much at least follows, I think, from the admission that the one reality does in any case manifest itself in a medium external and foreign to itself. If it can thus disguise its unity sufficiently to appear as a vast plurality of more or less independent parts, what right have we to set any limits to its powers of masquerading? And so we may perhaps admit that Plato's argument is independent of the surreptitiously introduced $\dot{a} \in \dot{ } i^{\text {. At }}$ At the same time, one cannot help feeling that the ambiguity created by the aei may have served, like the ambiguity of the $\pi$ ou and $e^{\nu} \tau \iota \nu \iota$ in the previous case of extension, to give the argument for Plato the delusive appearance of a rigid deduction of pinenomena from first principles.

We proceed now from the two prominent features of the visible world, extension and motion, to the most general of qualitative relations-identity, difference, likeness, unlikeness. We may assert one of two, or at any rate one of three, relations 
about any two subjects we please. Either they are the same, or they are different, or lastly, in the case where we can predicate neither of these relations, one of the things stands to the other in the relation of part to whole. Two of these relations may at once be denied of the One. It is not a part of itself, and it is not anything different from itself. Only one possibility remains. The One is identical with itself. But yet again we have seen that the "One" or reality is in some sense "outside itself,"

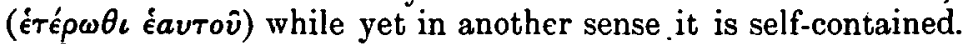
And as these two aspects are different it must be true to say that the same reality as existing "outside itself" is different from itself as self-contained. Thus the real is both identical with and different from itself. Again there must be a difference between unity and whatever is not unity. Unity or the One is therefore different from the multiplicity which exists side by side with it. And from this, on the principle that identity and difference are irreconcileable, we might be inclined to deny that

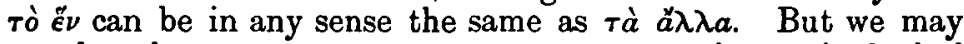
see that the attempt to carry our own assumption to its logical conclusion would yield the opposite result. This is proved as follows. Identity and difference are, we say, absolutely irreconcileable. But it follows at once that difference cannot have any place in the world. For if difference persist even for a moment, then for that space of time it has proved itself compatible with the continued identity of the subject in which it exists, and thus

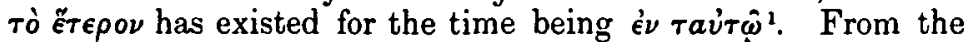
alleged incompatibility of identity and difference it follows therefore that difference can exist neither in the One nor in the Many. And as they cannot be different in virtue of a mere act of "position" without presenting definite points of distinction,

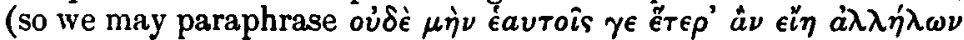

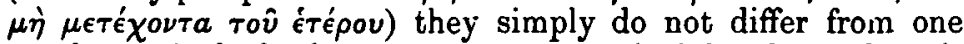
another. And further on our own principle that what is different cannot be in any way identical we must not conceive

1 This argument reads to us very like a sophism. Nothing is more obvious than that it only proves that if a thing $d$ exist at all it must at any moment be identical with and different from itself at any other moment of its existence. It has not proved what we want, viz., that $A$ cannot be different from $B$ which coexists with it without also being in some way identical with $B$. To us it seems self-evident that $A^{\prime}$ s identity with $A$ does not in any way conflict with its difference from $B$, nor help in the least to establish its identity with $B$. But this conception of an $A$ which has opposite predicates according as it stands in relation with different things is just what the believers in such a unity as Plato is refuting refuse to entertain. Their position is this. Either $A$ is identical or it is different, and they will not allow you to say, "It is both-it is identical with $A$ and different from $B$." So that against them the argument holds good. 
of the Many as a number of units: that : vould be to ascribe to the manifold the very unity we wish to denv of it. So that the One is not related to the Many as part to whole (147 A). Nor yet as whole to part for tije same reason. But we have previously decided that if two things are neither different nor yet related as whole and part they are the same. Thus the very attempt to be logical in our assertion of the absolute difference between unity and multiplicity leads to their absolute identity. Thus, summing up, the one reality is at once identical with and different from itself and the manifold it presupposes. Or, as we may expand the statement, what is real is a single whole which nevertheless appears as a multiplicity of parts, and it contains nothing but the parts, while it is not any one of them nor all of them taken together.

From the establishment of relations of identity and difference between the One and itself and other things we can now go on to establish those of likeness and unlikeness. For, Plato argues, $(147 \mathrm{C}-148 \mathrm{~A})$ the very fact that the $\mathrm{One}$ and the many are different implies that they are also alike. You say not only "the One is different from the Many," but also "the Many are different from the One," and the difference referred to in the two judgments is one and the same. The same identical quality has appeared twice over, once as a predicate of the One and again as a predicate of the Many (147 D-E); and things which have an identical predicate ( called "like." Thus just in so far as the One and the Many are different they are also alike. The conclusion is of course sound, but the reasoning is, I fear, more than doubtful. It seems hardly permissible to treat a relation between $A$ and $B$ as if it were a mere adjective which could be attached to either term by itself at pleasure, and then to postulate a new relation founded on the presence in both $A$ and $B$ of this same adjective. Even ordinary language recoils from such an attempt to make the relations "inhere in" their terms in this way, and takes refuge in the ambiguous word "between." (See Bradley, Appearance and Reality, p. 32, fontnote.) But in the Parmenides relation and quality are only beginning to be distinguished from one another.

To return to Plato's argument. The One is once more not only like but also unlike the Many. For, as we have seen, it is not-only different from but also identical with them. And since difference implied likeness, identity being the contrary of difference will imply the opposite relation of unlikeness. And yet again we may reverse this result. For in so far as two things are of identical quality ( $\tau a \dot{\epsilon} \tau \dot{o} \pi \dot{\epsilon} \pi o \nu \theta \epsilon \nu$ ), their quality does not differ, and they are therefore not unlike but like, while in so far 
as two things have different qualities they are unlike (148 c). Thus both the identity of the single reality with a multiplicity and its difference from it imply the double relation of likeness and unlikeness. And since we have seen that reality is both identical with and different from itself it must stand to itself also in the same complicated relations. So that it is both like and unlike itself and its opposite.

Parmenides next asks (148 D) does the One stand or does it not stand in relations of contact with itself and with the plurality it implies? It is impossible to say how far the spatial language of the following argument (ä $\pi \tau \epsilon \sigma \theta a \iota, \chi \omega ́ p a$, $\dot{\epsilon} \phi \epsilon \hat{\eta} \hat{\eta}$ ) is literal or how far it may be simply metaphorical. How little violence would be done to such language by taking it as in the main symbolical we shall easily see if we reflect on the extent to which, even in English, we have to employ such terms as "aspect," "thread of connection," "points of contact," to denote relations of an entirely non-spatial kind. And I think we may say that Plato's reasoning, while ostensibly confined to spatial contact, will apply with equal force to any conception of the mutual interrelation of reality and its various "parts." Inasmuch as the whole is self-contained we may speak of it as "in contact" with itself; and, again, inasmuch as it is contained, as we have already learned, in what is not itself $(\dot{\epsilon} \nu \not{a} \lambda \lambda \omega)$ it will again be in various relations of "contact" with this multiplicity which contains it (148 E). So too we cannot avoid sometimes distinguishing, or seeming to distinguish, between the single unity of the world-plan and the multiplicity in which it is carried out, and we then say, in more modern but equally spatial phraseology, that the general scheme of the whole assigns to the particulars their proper places, or, again, that the particular is what it is in virtue of its manifold connection with the whole.

But, on the other hand, such expressions are not true without qualification. For contact (148 E) only takes place between two bodies which occupy adjacent places. And reality is one and not two; and since it cannot become two there is no second reality for it to be in contact with: it cannot therefore strictly be said to be in contact with itself. Nor yet with its complement and opposite. For one act of contact is only possible between two definite points, two contacts between three points, and so on. Contact in general, that is, is only possible at definite points, and the plurality which we think of as the counterpart of unity must not even be taken to present a number of definite distinguishable points. For to make that plurality into a definite number of units is to introduce into it the conception of unity. Considered in ab- 
straction from unity, as its complement and opposite, it can only be thought of as a vague and as yet undetermined Mehrheit, (cf. the relations between the äreipov aud the $\pi \dot{c}$ pas at $158 \mathrm{D}$ and in the Philebus) which presents no definite points at which the One may enter into contact with it. Thus the one reality not only is but also is not in "contact" with itself and with its inherent multiplicity. To revert to our former illustration from modern phraseology, we can easily see that reality, strictly speaking, cannot enter into relations with itself, and when we talk as if it could we are making a necessary but ultimately untenable distinction. For ultimately the whole which, as we say, assigns their "places" to the "parts" and the "parts" themselves are one and the same single reality. There are thus ultimately not the two terms which are essential to "contact" or "relation." And clearly reality can stand in no relations to what is beyond it and so merely unreal.

We must now turn from the most universal qualitative to the most general quantitative predicates. We are to see that the One is, according to the way in which you look at it, alike capable and incapable of the various relations of equality and inequality with itself and its opposite $(149 \mathrm{D}-151 \mathrm{E})$. The reasoning, which is unfortunately far from being cogent, proceeds thus. Here, as in previous cases, we begin by pointing out that if the One enters into these relations it cannot be

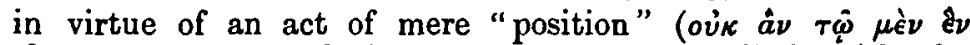

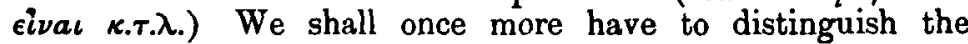
"unity" of the One and the "plurality" of its counterpart, which constitute their inmost essence, from the non-essential "greatness" and "smallness" which we predicate of them. Or, in the familiar Platonic phraseology, if these predicates of "greatness" and "smallness" are to attach to reality in any way, we must be able to affirm the real existence of two Forms or Ideas, "greatness" and "smallness," by "possession" of which reality is entitled to be called "great" or "small." Very well ; but if "smallness" is present in the One at all, it must qualify either a part or the whole of it. But "smallness" cannot attach to reality as a whole, for in that case it is either equal in extent to it or extends beyond it. The "small" will either be another name for the one reality or it will be something still more comprehensive. Either supposition is absurd: the "small" is that which is smaller than, not that which is equal to or greater than something else. Thus this "smallness" is not a predicate by which you can qualify reality as a whole. And the same reasoning holds good of any subordinate part of reality you choose to consider. Smallness there- 
fore is not a quality of reality as a whole nor of any part of it taken by itself, and nothing can be truly called "small" except the abstraction "smallness" itself. And of course with the disappearance of "smallness" its correlate "greatness" also vanishes. Thus reality and its parts cannot be said to be greater or smaller than each other, nor can any such relation subsist between reality and the abstractions "smallness" and "greatness" themselves; for they, in virtue of the principle invoked by Parmenides at $133 \mathrm{c}$, are relative only to one another. But when one of two things is neither greater nor smaller than the other, neither exceeds it nor falls short of it, they stand in the relation of equality and are called equal. The one reality will therefore be equal both to itself and to its parts (150 E). Yet this conclusion is not the whole truth; for, as we have already seen, reality is self-contained; we may then once more distinguish between reality as containing and the same reality as contained, and we may say that the one reality is at once greater and less than itself. Or, perhaps one might expand this result; we are driven on the one hand to take reality as = the whole contents of the world-plan, while on the other doubts arise as to whether what is past and what is still to come are not unreal; there can be nothing unreal in the one reality, and yet, unless becoming is a mere empty delusion, there seem to be parts of it which are no longer or are not yet fully real.

This conclusion is still more manifestly what Plato has in his mind as he proceeds to describe the relation of tò $\tilde{\epsilon} \nu$ to $\tau \dot{a} a ̈ \lambda \lambda a$. What is nowhere, he continues, is nothing; what is and is real must manifest its reality at some definite pointmust, as he phrases it, be "in something." And as there is no third reality over and above the One and its counterpart the Many, the One and the Many must "be in" one another. The One, that is, is only real so far as it realises itself by appearing in the plurality, the Many only real in so far as they are the appearance of the One. And in so far as you speak of the One appearing "in" the Many, it would seem to be less than they, while, in so far as the Many only exist in the One, they appear to be less than it. Or, to revert to our expansion of the argument, in so far as reality is only that which makes itself felt as present reality, there are past and future elements of existence which we must call unreal; but, in so far as the ultimate reality is an indivisible whole, what is present reality at any moment falls far short of being the whole reality. Thus, in conclusion, in one sense or another, all three relations of equality, excess. and defect can be asserted-or denied-to hold good between the One and the 33 
many (151 B). The extension of the argument from merely quantitative to definitely numerical predicates follows naturally, and we need not stop to consider it in detail. On the latter or affirmative part of this piece of reasoning it is not perhaps necessary to make any remark; my paraphrase has already sufficiently explained what seems to be the general sense of it. The negative argumentation however is of so peculiar a character that it must not be passed without a word of comment. I have already called attention to the important point that Parmenides begins his argument at $149 \mathrm{E}$ by asserting that "greatness" and "smallness" can only belong to a subject in virtue of its participation in the corresponding "Form"-a coincidence between the teaching of our dialogue and that of the Plaado which shows how far Plato was when he wrote the Parmenides from entertaining that objection to "Ideas of relations" which is shared with Aristotle by several modern scholars. The reasoning which is based upon this principle is unfortunately more open to criticism than the principle itself, which has only been decried when it has been first misunderstood. It is easy, of course, to see that Plato's general contention is perfectly correct. If you treat a relation such is that of "more and less" which can only exist between two terms as if it were a quality that could attach to either term taken by itself you are led to illegitimate or absurd results ${ }^{1}$; and it is quite certain that "res absolute in se spectatie" are neither great nor small. But Plato does not seem to be at all adequately aware of the monstrous character of the confusion in question, and here, as once before in the Parmenides, and frequently enough in other dialogues, we have painful evidence that he had not the advantage of writing with Aristotle's table of categories before him, and that the difference between a "quality" and a "relation" was by no means clearly fixed in his mind. Hence, side by side with antitheses both the positive and the negative parts of which are of high importance for a true understinding of the world, we have, in the present case, one of which the negative half contains so little truth that is hardly worth calling a truism and might easily be mistaken for a sophism. And still more serious objections, which are too obvious to need pointing out, can be brought against the inference that whenever tivo things do not stand in the relation of "more and less" they are equal.

We come now (151 E-155 D) to the final step in the long and intricate argument of the second hypothesis. It will be

1 We found Plato himself making a similar blunder at $147 \mathrm{D}, \mathrm{E}$. 
remembered that the result which was immediately fatal to the reality of $\tau \dot{o} \tilde{e} \nu$ in the first hypothesis was its failure to appear in the time series. For, though a thing might conceivably be real without possessing some of the other predicates which have been canvassed, it seems only too manifest that what never succeeds in making its presence felt is, at least for us and for any philosophy we can create, nothing at all. Hence the climax of the procedure by which we have laboriously vindicated for reality the various predicates of the actual world will be our proof, if we are able to give one, that the unity of the real is compatible with the conflicting determinations to which all that appears in time is, as we have seen, liable. We begin our demonstration with the temporal relations of the real One to itself taken as a whole. And first as to the main point, the possibility of time predicates in general. Once more we remind ourselves of our original starting-point, which was that the ultimate reality-whatever it is not-is something real. And we once more have recourse to a principle which has served us well already - that that cannot be real which does not appear as present reality. To be real $(151 \mathrm{E}-1.52 \mathrm{~A})$ is to be real in the present, just as to have been real means to have once been present reality. Hence, from the reality of the One, we can conclude at once that it must make itself felt in a present, and thus appear in time. And if it appears continuously in time the real nust be constantly becoming posterior and consequently also prior to itself. And becoming is only thinkable as a constant transition out of the present into a future which is not as yet present. And so, at any moment at which we choose to think of this process as arrested, we may say that the One not only is becoming but has become and actually is both prior and posterior to itself. But again the various present moments taken together make up the whole period of the One's existence, and consequently we may say that throughout its whole existence it is perpetually in this double relation of priority and posteriority to itself. While lastly, taking the whole period of its existence as one eternal present, we may say with equal truth that it neither becomes nor is prior nor posterior to, but is for ever simultaneous with, itself. Again, with reference to the relation between the one reality and its parts, we may make similar judgments. For the one reality is a unity and its parts a multiplicity. And on the principle that the simple is prior to the complex, we must hold that the one reality is prior to the manifold in which it appears. But yet again the plurality is a plurality of parts of the one real, and the whole reality therefore seems not to exist until all its parts-beginning midulle and end-have successively become real, and thus 
it would appear that the Many are once more prior to the One. Lastly, as we are now convinced, each of the many parts is itself a unity, and thus each involves that systematic character which is distinctive of the One; so that the One and the Many are simultaneous. Summing up then, the One stands not only to itself but also to the Many in all three relations of simultaneity, priority, and succession. In like manner we may say of what we call the Uniformity of Nature that while its previous existence must be presupposed in every attempt to explain any set of facts, so long as there remain any facts to come it seems not to be fully realised, while yet we cannot resist the conclusion that ultimately it and it alone is the one ever-present reality. Here the consideration of the temporal relations of rò $\ddot{\epsilon} \nu$ might profitably end, but Plato goes on in the spirit of paradox to develop a further set of contradictions which are entirely without metaphysical significance and are only reached by manifest sophistry. We have seen that the One both is and is not prior and posterior to the Many; can we say that it always and never is becoming prior and posterior to them? The arguments which are produced to justify a conclusion on this point are almost untranslateable and turn on a mere quibble or equivocation

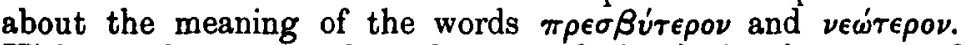
Hitherto these terms have been used simply in the sense of prior or posterior; Plato now takes them literally as = "older" and "younger," and moreover-with an ambiguity which can

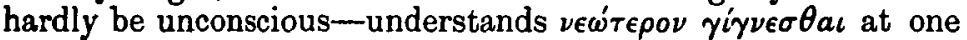
time to mean a reduction of the actual interval by which one person or thing is said to be "older" than another, at another the diminution of the proportion between this interval and the whole "age" of the persons or things in question. In the former sense it is clear that neither $\tau \dot{0} \tilde{\varepsilon} \nu$ nor anything else can ever become "younger" or "older" than that with which you compare it. What is once "older" or "younger" than something else by a given quantity of time-say, two yearswill always be "older" or "younger" by just that same interval. Thus we may say that, as we have shown, the One is, and has become, but never that it is becoming "older" or "younger" than its many parts. And yet, on the other hand, as time goes on, the interval in age between two things is perpetually growing less, relative to their whole duration. A man of sixty, Plato perhaps reflected, can hardly be said, for any but the most superficial purposes, to be as much older than a man of fifty as a youth of twenty is older than a child of ten. Thus we may say that the older of two things is always growing younger with respect to the other and the younger older, and this process 
though never ceasing never exhausts itself; the interval however much reduced never vanishes. Hence, as we have shown that either the One or the Many may at pleasure be regarded as prior to the other, we may say of both that each is perpetually becoming, though it never finally becomes, at once "younger" and "older" than the other $(155 \mathrm{c})$, and with this problematic result our investigation of the puzzling relations of the one reality to its parts in time comes to an end.

Finally, it only remains to draw the formal conclusion from the appearance of reality in the time series. As so appearing it can be qualified by all the determinations "is," "was," "has been," "will be." And each of these time-determinations can be combined with the attribution to it of all sorts of qualities

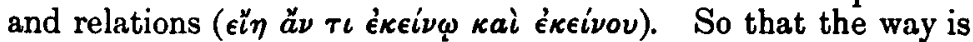
open for the reference to the one reality of all the varied judgments as to what is, has been, or will be, which make up the body of our knowledge. And indeed the very fact of our being able to make it the subject of our present discourse and thought etc. $(155 \mathrm{D})$ shows that it is accessible to knowledge, opinion, and

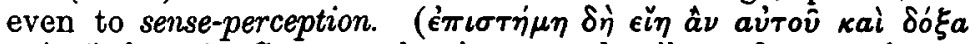
$\kappa a i$ aĭ $\sigma \eta \eta \iota_{\iota}$.) So, reversing in every detail our first result, we add it can have and actually has theories formed about it and a name bestowed on it: and, in short, whatever is true of any object of knowledge quà object of knowledge is also true about

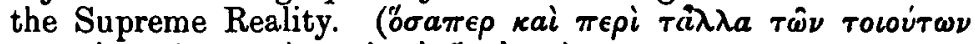

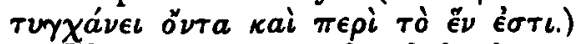

Thus the nett result of the long and complicated reasoning of $142 \mathrm{~B}-155 \mathrm{E}$ is this: that if we once start with the conviction that the ultimate reality must at least be real we are driven so to conceive of its unity as to permit the recognition of all the diversity of the actual world as falling somehow within it. Every affirmation and every negation that can significantly be made about anything in the world will come in the end to be a partial statement of the nature of the single and ultimate reality. Judgments which assert the world's unity or its diversity, which attach to it spatial, temporal, qualitative and quantitative relations of the most various kinds will all have their own truth, while nove will be the whole truth. This last qualification is added advisedly; it seems to me to be the main if not the only function of the negative side of the successive contradictions of the argument to remind us that every assertion we can make about the real on the strength of our experience is, though true, only a part of the truth. And I hope I am not reading modern notions into Plato when I say that $I$ find the underlying idea of the whole in the conception 
of a reality which, while it can only be real because it realises itself in the details of experience, is never fully realised in any of them. I shall recur to this conception later on. Meanwhile there remain two points, both of some importance, to which I would call attention before finally leaving the hypothesis over which we have delayed so long. The first point is one to which I have already devoted a few remarks, the entire absence of anything like Hegelianism from the antitheses of Parmenides. What I have already said on this subject is, I think, fully borne out by the argumentation we have passed in review. We have, it is true, been presented with a series of antitheses each side of which has been equally asserted as true; but there has been no attempt either to present inner contradiction as characteristic of every conception nor, which is the special property of Hegel, to treat the various categories under which we think of the real as begotten out of one another by the attempt to reconcile this contradiction. We have, indeed, in the case of the conceptions of unity and sameness had a demonstration that each directly presupposes its own opposite, but in the remaining cases Plato has been content with simply proving first one side and then the other of the contradiction by supplying on each occasion the conditions under which the judgment holds good, without any attempt to make the one side of the antithesis arise, by a dialectical necessity, from the other; while in more than one case, notably in that of the puzzles connected with time, the antithesis combines elements which have real philosophical significance with others which are little better than quibbles. (Compare also my abstract of the next hypothesis.)

The second point to which I would call attention is to my mind of much greater importance. We saw that Plato in concluding the argument at $15 \bar{J} \mathrm{D}$ asserts that $\tau \dot{\dot{c}} \tilde{\epsilon} \nu$, the supreme reality, can be the object not only of full and adequate knowledge but even of opinion and sense-perception. The bearing of this passage on certain views both ancient and modern is obvious. Taken in connection with the attack

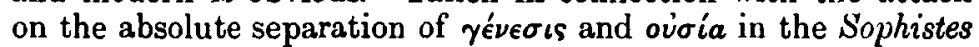
and Theaetetus (Soph. $248 \mathrm{ff}$., Theaetet. $155 \mathrm{E}$ ), and the conception

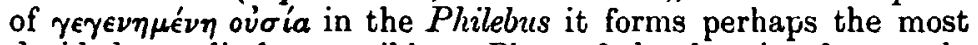
decided repudiation possible to Plato of the doctrine frequently ascribed to him by persons whose knowledge of his system is derived from a superficial reading of the Republic, that the world of knowledge and the world of perception are two different worlds, and not the same world more or less adequately apprehended. And it thus on the one hand serves to mark most emphatically the difference between the Platonic One and such a unity as was asserted in the physical sphere by 
the Eleatics and in the metaphysical by the Megarians, while on the other it answers by anticipation the statement of Apelt that Plato treats sensible appearance as mere Nicht-Seym, and the theory of English believers in the "transcendence " of the Idea that sense-perception is the merely shifting and unstable. With regard to the "transcendent" Ideas of Megarianism one might say that the whole of hypotheses 1 and 2 are no more than the elaboration in detail of the contrast which Plato draws more briefly and more rhetorically in the Sophistes between a reality that stands "moveless and mindless" like an "holy image" and a reality which is fraught with "motion and soul and life." (Soph. 24.9 A.)

We might now, it would seem, bring our argument to a close. In principle the task of Parmenides has been accom"plished. It has been shown, that on that theory of the nature of the world's unity which resulted logically from the position of the youthful Socrates, all assertion and all denial about reality are alike impossible, while on a rival theory both are intelligible. It would therefore be natural to conclude that the one theory had successfully established itself as against the other, and with this result the dialogue might have come to an end. In the Parmenides however as in the Republic Plato is not satisfied with the mere direct establishment of his thesis. It must be further confirmed by corroborative evidence and the production of negative instances. Thus we have still to consider in detail what will be the bearing of the two rival doctrines on the position of $\tau \dot{a} a \dot{a} \lambda \lambda a$ - the world of change and multiplicity(Hypotheses 3-j) and what will follow from their denial (Hyp. 6-9). 